\title{
Use of DPP-4 inhibitors in type 2 diabetes: focus on sitagliptin
}

This article was published in the following Dove Press journal:

Diabetes, Metabolic Syndrome and Obesity:Targets and Therapy

27 March 2010

Number of times this article has been viewed

\section{Bo Ahrén \\ Department of Clinical Sciences, Lund University, Lund, Sweden}

Correspondence: Bo Ahrén Department of Clinical Sciences, Division of Medicine, BII BMC, SE-22I 84 Lund, Sweden

Tel +46462220758

Fax +46462220757

Email bo.ahren@med.lu.se
Abstract: Inhibition of dipeptidyl peptidase-4 (DPP-4) prevents the inactivation of glucagonlike peptide-1 (GLP-1). This increases circulating levels of active GLP-1, stimulates insulin secretion and inhibits glucagon secretion, which results in lowering of glucose levels and improvement of the glycemic control in patients with type 2 diabetes. This review summarizes experiences with DPP-4 inhibition in the treatment of type 2 diabetes, with a focus on sitagliptin. Sitagliptin has in several clinical studies been shown to improve metabolic control in type 2 diabetes, both when used as monotherapy and when used in combination with metformin, sulfonylurea, thiazolidinediones or insulin. The reduction in $\mathrm{HbA}_{1 \mathrm{c}}$ is $\approx 0.6 \%$ to $1.0 \%$ from baseline levels of $7.5 \%$ to $8.7 \%$ over 6 to 12 months therapy. Sitagliptin has a favorable safety profile, is highly tolerable, and there is a minimal risk of hypoglycemia. Furthermore, sitagliptin is body weight neutral or induces a slight body weight reduction. Sitagliptin may be used in the early stages of type 2 diabetes in combination with metformin or other treatments in subjects with inadequate glycemic control on these treatments alone. Sitagliptin may also be used in monotherapy and, finally, sitagliptin may be used in combination with insulin in more advanced stages of the disease.

Keywords: glucagon-like peptide-1, dipeptidyl peptidase-4, type 2 diabetes, sitagliptin, treatment

\section{Introduction}

Hyperglycemia is a key factor underlying complications of type 2 diabetes, and, therefore, reducing hyperglycemia is a critical aim of treatment of the disease. Improving hyperglycemia has thus been shown to reduce the risk of microvascular complications and may also reduce macrovascular complications. ${ }^{1,2}$ The basis for treatment is lifestyle changes with increased physical activity and dietary modifications. If these treatments are not sufficient, pharmacological treatment with metformin is recommended. ${ }^{3}$ However, due to the progressive nature of the disease, additional pharmacological treatment is often required. Several options exist: sulfonylureas, thiazolidinediones, meglitinides, $\alpha$-glucosidase inhibitors and insulin., ${ }^{3,4}$ There are, however, limitations with these pharmacological treatments, such that even with aggressive treatment using these approaches, glycemic control often deteriorates. Furthermore, current therapy is often associated with adverse events. These adverse events include hypoglycemia with sulfonylureas and insulin, gastrointestinal discomfort with biguanides (such as metformin), and increased body weight, edema and cardiac insufficiency with thiazolidinediones. ${ }^{5-8}$ Furthermore, the current therapies do not target all pathophysiological aspects of type 2 diabetes. Thus, dysregulation of glucose metabolism in type 2 diabetes is caused by a combination of insulin resistance, impaired insulin secretion, augmented glucagon 
secretion and reduced $\beta$-cell mass. ${ }^{9-12}$ Whereas insulin resistance is treated by biguanides and thiazolidinediones, and insulin secretion is treated by sulfonylureas, no therapy treats the hypersecretion of glucagon and the reduced $\beta$-cell mass. There are thus several unmet needs in the treatment of diabetes which urge the development of novel treatment.

Recently, several new approaches have emerged to meet these challenges. These novel therapies include the amylin analog pramlintide and the GLP-1 receptor agonists, including exenatide and liraglutide. ${ }^{13-15}$ Another novel class of compounds is inhibitors of the enzyme dipeptidyl peptidase-4 (DPP-4). The DPP-4 inhibitors, which prevent the inactivation of the incretin hormones glucagon-like peptide-1 (GLP-1) and glucose-dependent insulinotropic polypeptide (GIP), increase the endogenous concentrations of these hormones which prolongs their actions and improves glycemia. ${ }^{16-20}$ Several DPP-4 inhibitors have been developed and are in various stages of clinical development. Sitagliptin, vildagliptin and saxagliptin are approved for use in several countries. ${ }^{20}$ This article reviews evidence for clinical use of DPP-4 inhibitors, with a focus on sitagliptin.

\section{Incretin-based therapy}

GLP-1 is released from the gut following meal ingestion and GLP-1 in turn stimulates insulin secretion and inhibits glucagon secretion, which reduces glucose levels. ${ }^{16,17}$ GLP-1 is, however, rapidly inactivated by the enzyme DPP-4, which cleaves the two N-terminal amino acids of the hormone making it largely inactive. ${ }^{16}$ This process is efficient; the half-life of active GLP-1 is less than 2 minutes. Inhibition of DPP-4 prevents therefore the rapid inactivation of GLP-1. A major mechanism underlying the antidiabetic action of the DPP-4 inhibitors is thus the increased concentrations of active GLP-1 as has been demonstrated by vildagliptin following meal ingestion. ${ }^{21}$ As a consequence, DPP-4 inhibition increases insulin secretion and inhibits glucagon secretion, which results in inhibition of hepatic glucose production, as demonstrated for vildagliptin. ${ }^{21-23}$ These actions reduce both fasting and prandial glucose levels and the 24-hour glucose profile, as has been shown for NVP-DPP728 and sitagliptin. ${ }^{24,25}$ Rodent studies have also shown that DPP-4 inhibitors (vildagliptin and sitagliptin) increase islet mass and normalize islet cell topography in diabetes models in mice. ${ }^{26,27}$ This would suggest that DPP-4 inhibition targets the important islet dysfunctions in type 2 diabetes. It should be emphasized, however, that no evidence of increased $\beta$-cell mass by DPP-4 inhibitors exists in humans.

DPP-4 inhibition has been shown to be efficient in improving glycemia both as monotherapy and as add-on to metformin, sulfonylurea and thiazolidinediones in subjects with inadequate glycemic control. DPP-4 inhibition has also been shown to be safe, highly tolerated and body-weight neutral. ${ }^{18-20}$ In fact, DPP-4 inhibition meets several of the challenges of the treatment of today - it improves glycemia with little risk for hypoglycemia, it does not increase body weight, it is safe with very little risk for adverse events, and, due to its targeting of the key islet defects, it has the potential to modify the disease process.

\section{Sitagliptin - pharmacokinetics and mechanisms of action Structure and pharmacokinetics}

Sitagliptin is a triazolopiperazine derivative (Figure 1). ${ }^{10}$ It is orally active and it selectively and reversibly inhibits DPP-4 compared to inhibition of other members of the DPP family. Thus, in vitro studies have shown that at $18 \mathrm{nmol} / \mathrm{L}$, sitagliptin inhibits DPP- 4 by $50 \%$ whereas $48 \mu \mathrm{mol} / \mathrm{L}$ is required to inhibit DPP- 8 by $50 \%$ and $>100 \mu \mathrm{mol} / \mathrm{L}$ is required to inhibit DPP- 9 by $50 \%{ }^{28}$ The pharmacokinetics of sitagliptin have been examined in both healthy subjects ${ }^{29}$ and in subjects with type 2 diabetes $^{30}$ with no difference between these groups. Sitagliptin is rapidly absorbed after oral ingestion with an $87 \%$ bioavailability after intake of a

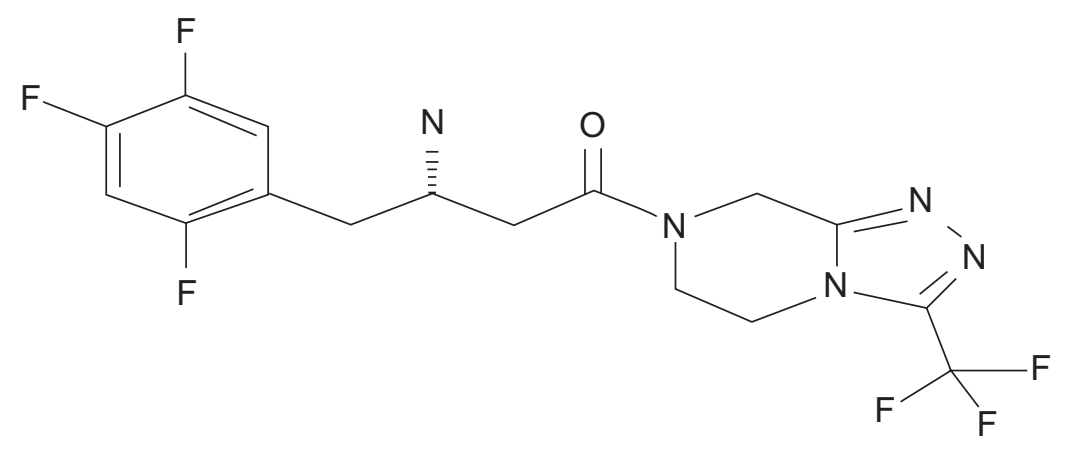

Figure I Structure of sitagliptin. 
single $100 \mathrm{mg}$ tablet. ${ }^{31} \mathrm{C}_{\max }$ is observed within 1 to 2 hours and the half-life of the compound is $\approx 12$ hours. ${ }^{31}$ Sitagliptin is minimally metabolized and $\approx 80 \%$ of the compound is excreted unchanged in the urine.$^{32}$ Renal excretion is achieved through a combination of active secretion and glomerular filtration. ${ }^{29}$ Renal insufficiency increases circulating levels of sitagliptin in that plasma levels of sitagliptin are increased by 2 -fold in patients with moderate renal impairment (creatinine clearance $30-50 \mathrm{~mL} / \mathrm{min}$ ) and by 4 -fold in patients with severe renal impairment (creatinine clearance $<30 \mathrm{~mL} / \mathrm{min}$ ), making dose adjustements recommended in these patients. ${ }^{33}$ Hepatic insufficiency, obesity and old age do not seem to alter the pharmacokinetics of sitagliptin and no drug interactions have been observed for the compound.

\section{Mechanisms of action}

Sitagliptin rapidly inhibits DPP-4 after oral ingestion, and within 1 hour, DPP-4 activity, as determined in plasma, is inhibited by more than $90 \%{ }^{30}$ The duration of DPP-4 inhibition is such that the drug can be dosed once daily. The inhibition of DPP-4 activity is dose-dependent and is sustained after multiple dosages, as demonstrated in studies up to 28 days. ${ }^{30,33,34}$ Active GIP and GLP-1 levels are increased by sitagliptin by approximately 2 - to 3 -fold after meal ingestion or oral glucose..$^{30,33,34}$ This results in increased insulin secretion as judged from increased insulinogenic index ${ }^{35-40}$ and the homeostasis model of assessment of $\beta$-cell function (HOMA- $\beta$ ). ${ }^{36-46}$ Improved $\beta$-cell function is also evident from reduced proinsulin to insulin ratio. ${ }^{38,41-44,47}$ Sitagliptin also reduces glucagon levels, ${ }^{25,30}$ although this needs to be examined in more detail. The improved islet function by sitagliptin results in reduction of both fasting glucose and prandial glucose as revealed in different studies in subjects with type 2 diabetes. ${ }^{25,36,48,49}$ In fact, the entire 24-hour glucose profile is reduced by sitagliptin, as is evident from a study examining addition of sitagliptin to ongoing metformin therapy compared to metformin treatment alone (Figure 2). ${ }^{25}$

\section{Sitagliptin - clinical effects in monotherapy Placebo-controlled studies}

Sitagliptin was initially evaluated as monotherapy for 12 weeks in dose-findings studies in drug-naïve patients with type 2 diabetes. At the dose of $100 \mathrm{mg}$, hemoglobin $\mathrm{A}_{1 \mathrm{c}}\left(\mathrm{HbA}_{1 \mathrm{c}}\right)$ was reduced by sitagliptin by $0.6 \%$ from a baseline of $7.7 \%$ in one study comprising 555 subjects $^{50}$ and by $0.8 \%$ from a baseline of $7.8 \%$ in another study of 743 subjects. ${ }^{45}$ A subsequent placebo-controlled, multi-center 18-week study in 521 patients showed that sitagliptin at $100 \mathrm{mg}$ or $200 \mathrm{mg}$ once daily reduced $\mathrm{HbA}_{1 \mathrm{c}}$ by $0.6 \%$ and $0.5 \%$, respectively, from a baseline of $8.1 \%{ }^{42}$ and a 24 -week study using sitagliptin at 100 $\mathrm{mg}$ or $200 \mathrm{mg}$ daily in drug-naïve patients with a mean baseline

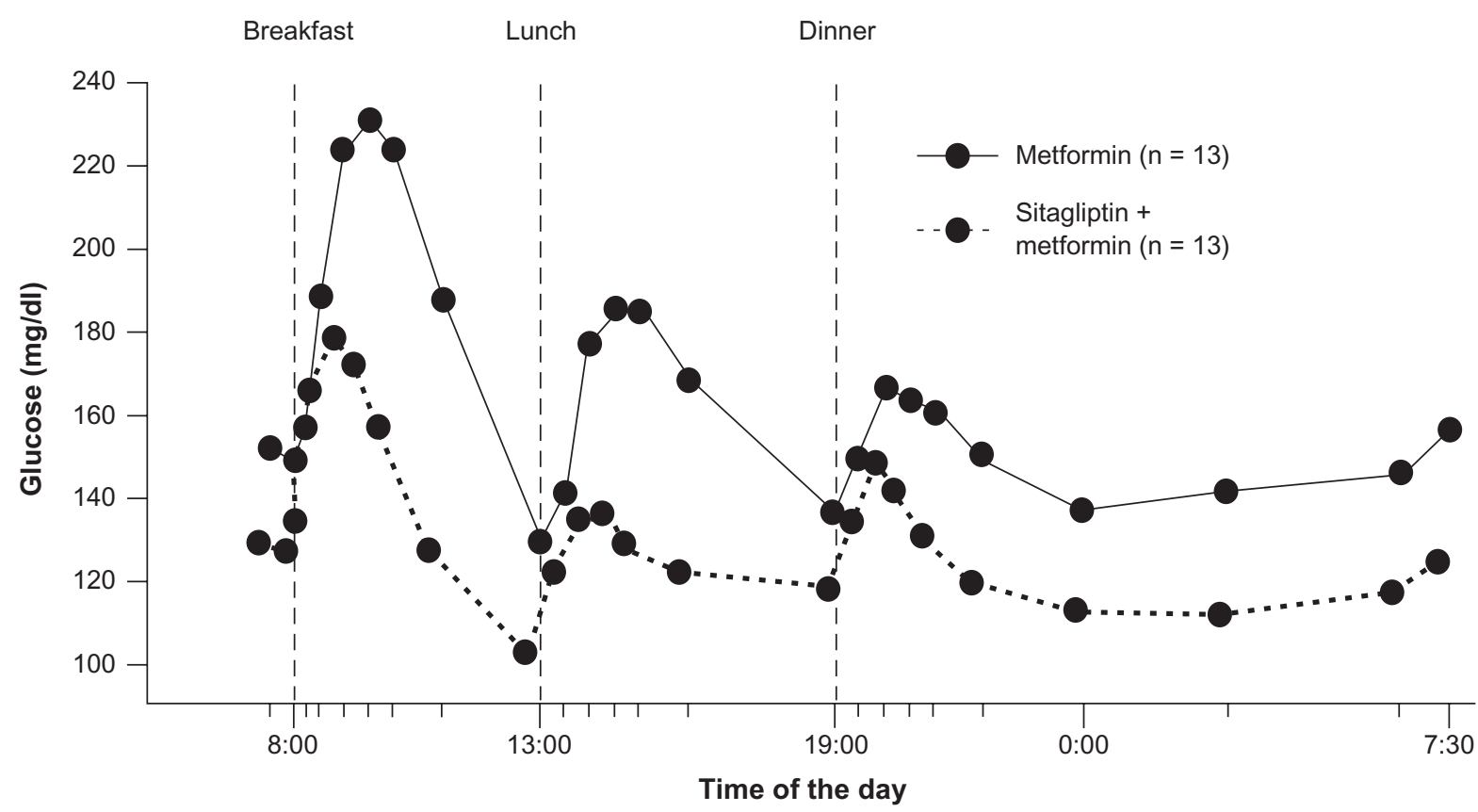

Figure 2 24-hour plasma glucose profile in patients with type 2 diabetes after four weeks treatment with sitagliptin (I00 mg daily) added to ongoing treatment with metformin compared to patients continued with metformin alone. Reproduced with permission from Brazg R, Xu L, Dalla Man C, et al. Effect of adding sitagliptin, a dipeptidy peptidase-4 inhibitor, to metformin on 24-h glycaemic control and beta-cell function in patients with type 2 diabetes. Diabet Obes Metab. 2007; 9:186-193.25 Copyright (C) 2007 Wiley-Blackwell. 
$\mathrm{HbA}_{1 \mathrm{c}}$ of $8.0 \%(\mathrm{n}=741)$ showed a reduction of $0.8 \%$ and $0.9 \%$, respectively. ${ }^{41}$ The improved glycemia during monotherapy with sitagliptin is sustained over at least 2 years, as shown in a 52-week study with an open label extension for another 52 weeks: sitagliptin at $100 \mathrm{mg}$ had after 2 years reduced $\mathrm{HbA}_{1 \mathrm{c}}$ by $0.7 \%$ from a baseline of $7.5 \% .{ }^{51}$ Sitagliptin has also been shown to efficiently improve glycemic control when used in monotherapy in a study comprising 530 Asian patients. Thus, one study showed that sitagliptin at $100 \mathrm{mg}$ daily reduced $\mathrm{HbA}_{1 \mathrm{c}}$ by $1.4 \%$ in Indians, by $1.4 \%$ in Koreans and by $0.7 \%$ in Chinese subjects with type 2 diabetes from baseline levels of $8.7 \%$ during 18 weeks treatment. ${ }^{35}$ Furthermore, in a study in 151 Japanese patients, sitagliptin at $100 \mathrm{mg}$ daily reduced $\mathrm{HbA}_{1 \mathrm{c}}$ by $0.7 \%$ from a baseline of $7.5 \%$ over a study period of 12 weeks in subjects with type 2 diabetes. ${ }^{36}$

Since sitagliptin is cleared by the kidney, dose adjustments are required in subjects with moderate or severe renal insufficiency. One study examined the 54-week efficacy and safety of sitagliptin as monotherapy in subjects with type 2 diabetes with moderate (dose $50 \mathrm{mg}$ daily) or severe (dose $25 \mathrm{mg}$ daily) renal insufficiency. Mean baseline $\mathrm{HbA}_{1 \mathrm{c}}$ was $7.7 \%$ and sitagliptin reduced $\mathrm{HbA}_{1 \mathrm{c}}$ by $0.7 \%$, ie, similar to those in other studies. ${ }^{52}$ Furthermore, sitagliptin was safe and well tolerated in the subjects with renal insufficiency, with a lower risk of hypoglycemia relative to glipizide and with weight loss compared with weight gain with glipizide. Another study has examined the influence of sitagliptin in elderly patients. In this placebo-controlled study of 123 patients with type 2 diabetes above 65 years of age, sitagliptin at $100 \mathrm{mg}$ over 24 weeks reduced $\mathrm{HbA}_{1 \mathrm{c}}$ by $0.7 \%$ from a baseline of $7.8 \% .{ }^{53}$ Sitagliptin was well tolerated in the elderly with low degree of adverse events and hypoglycemia occurring only in one subject, compared to two subjects treated with placebo.

\section{Sitagliptin - clinical effects when used in combination with metformin}

\section{Add-on to ongoing metformin}

Sitagliptin has been shown to improve glycemic control when added to metformin in subjects with type 2 diabetes who are inadequately controlled when treated with metformin alone. One study showed that in patients with ongoing metformin treatment $(\mathrm{n}=701)$ with a mean baseline $\mathrm{HbA}_{1 \mathrm{c}}$ of $8.0 \%$, sitagliptin at $100 \mathrm{mg}$ daily during 24 weeks, reduced $\mathrm{HbA}_{1 \mathrm{c}}$ by $0.7 \%$ when compared to subjects who maintained treatment with metformin alone. ${ }^{44}$ Sitagliptin progressively reduced $\mathrm{HbA}_{1 \mathrm{c}}$ levels during the first 12 weeks of treatment, and a sustained level was established thereafter. Also in Japanese patients, sitagliptin improves glycemic control when added to ongoing metformin treatment; the placebo-adjusted reduction in $\mathrm{HbA}_{1 \mathrm{c}}$ by sitagliptin was $0.7 \%$; baseline $\mathrm{HbA}_{1 \mathrm{c}}$ was $7.8 \%{ }^{37}$

\section{Comparison with active comparator}

One study compared the effect of sitagliptin (100 mg daily) with that of glipizide (up to $20 \mathrm{mg}$ daily) when added to ongoing treatment with metformin for a study period of 52 weeks in a total of 1172 patients with type 2 diabetes with a mean baseline $\mathrm{HbA}_{1 \mathrm{c}}$ of $7.5 \% .{ }^{54} \mathrm{HbA}_{1 \mathrm{c}}$ was reduced similarly by $0.7 \%$ in both groups (Figure 3 ). Sitagliptin (100 mg once daily) has also been compared with rosiglitazone ( $8 \mathrm{mg}$ daily) when added to ongoing metformin in subjects with

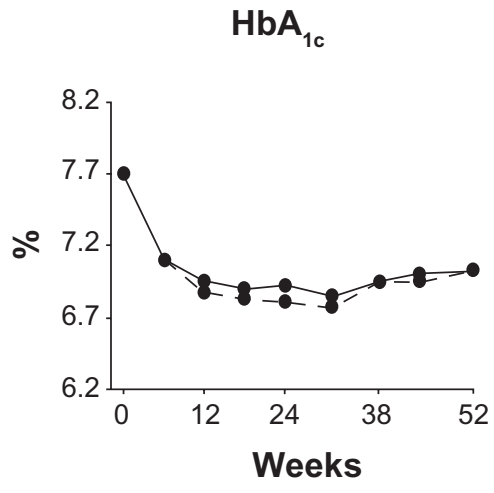

\section{Sitagliptin + metformin $(n=588)$}

Body weight

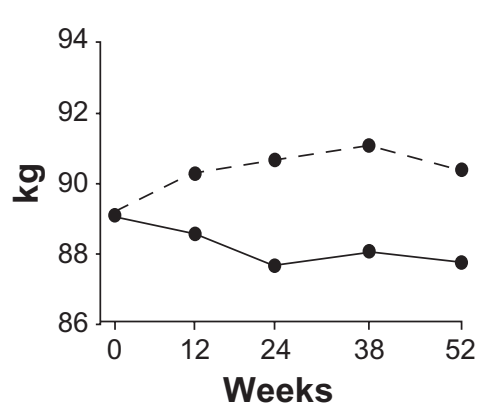

Hypoglycemia

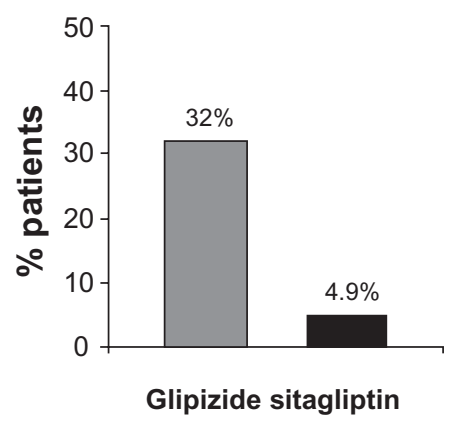

--- Glipizide + metformin $(n=584)$

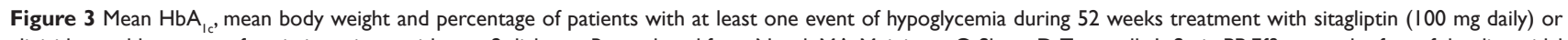
glipizide as add-on to metformin in patients with type 2 diabetes. Reproduced from Nauck MA, Meininger G, Sheng D, Terranella L, Stein PP. Efficacy and safety of the dipeptidyl peptidase-4 inhibitor, sitagliptin, compared with the sulfonylurea, glipizide, in patients with type 2 diabetes inadequately controlled on metformin alone: a randomized, doubleblind, non-inferiority trial. Diabet Obes Metab. 2007; 9:194-205. ${ }^{54}$ Copyright (C) 2007 Wiley-Blackwell. 
inadequate glycemic control with metformin alone (mean $\mathrm{HbA}_{1 \mathrm{c}} 7.7 \% ; \mathrm{n}=273$ ). After 18 weeks, $\mathrm{HbA}_{1 \mathrm{c}}$ was reduced by $0.7 \%$ by sitagliptin and by $0.8 \%$ by rosiglitazone; the difference was not significant. ${ }^{55}$

\section{Initial combination with metformin}

One study has examined the initial combination of sitagliptin (100 mg daily) and metformin ( 1 or $2 \mathrm{~g}$ daily) compared to monotherapy treatment with sitagliptin or metformin alone for 24 weeks $(n=1091)$ in subjects with mean baseline $\mathrm{HbA}_{1 \mathrm{c}}$ of $8.8 \% .^{43}$ Approximately half of the patients were drugnaïve, whereas the other half had received oral agents before. There was a marked reduction in $\mathrm{HbA}_{1 \mathrm{c}}$ after combination therapy (by $1.6 \%$ and $2.1 \%$ in the two groups differing in metformin dose, respectively). ${ }^{43}$ This study continued as an open-label extension for 104 weeks, thus providing 2-year data on sitagliptin when given in combination with metformin. A total of 1091 patients were included at start of the study, 587 entered the extension and 402 were included in the final analysis. Reduction from baseline $\mathrm{HbA}_{1 \mathrm{c}}$ was $1.4 \%$ and $1.7 \%$ in the two groups, respectively. ${ }^{51}$

\section{Sitagliptin - clinical effects in combination with agents other than metformin}

\section{Combination with pioglitazone}

Sitagliptin has been evaluated as add-on to ongoing treatment with pioglitazone in one placebo-controlled, 6-month study. ${ }^{47}$ The study evaluated addition of sitagliptin (100 mg daily) to pioglitazone at 30 or $45 \mathrm{mg}$ daily versus continuation with pioglitazone alone in patients with a mean baseline $\mathrm{HbA}_{1 \mathrm{c}}$ of $8.0 \%(\mathrm{n}=353)$. Sitagliptin reduced $\mathrm{HbA}_{1 \mathrm{c}}$ by $0.7 \%$ versus pioglitazone alone. ${ }^{47}$ Similar results of improved glycemic control when sitagliptin was added to ongoing pioglitazone treatment were also demonstrated in Japanese patients. ${ }^{39}$

\section{Combination with glimepiride}

Sitagliptin has as well been evaluated as add-on to ongoing treatment with glimepiride in a 6-month study of 441 patients with a mean baseline $\mathrm{HbA}_{1 \mathrm{c}}$ of $8.3 \%$. Sitagliptin (100 mg daily) reduced $\mathrm{HbA}_{1 \mathrm{c}}$ by $0.7 \%$ when adjusted for changes in the group continuing with glimepiride alone. ${ }^{46}$

\section{Combination with insulin}

One study evaluated the influence of sitagliptin (100 mg daily) when added to ongoing insulin therapy in a total of 617 patients with type 2 diabetes. ${ }^{56}$ Mean baseline $\mathrm{HbA}_{1 \mathrm{c}}$ was $8.7 \%$ and following addition of sitagliptin to the ongoing insulin therapy, $\mathrm{HbA}_{1 \mathrm{c}}$ was reduced by $0.6 \%$ versus no change $(0.0 \%)$ in patients who continued with insulin treatment alone.

\section{Sitagliptin - clinical effects when used in triple therapy Combination with metformin}

\section{and sulfonylurea}

A 6-month study evaluated addition of sitagliptin (100 mg daily) to a total of 441 patients with ongoing treatment with the combination of metformin and glimepiride with a baseline $\mathrm{HbA}_{1 \mathrm{c}}$ of $8.3 \% .{ }^{46}$ It was found that $\mathrm{HbA}_{1 \mathrm{c}}$ was reduced by $0.9 \%$ by sitagliptin compared to ongoing therapy with metformin and glimepiride.

\section{Combination with metformin} and thiazolidinediones

One study has examined the effect of addition of sitagliptin (100 mg daily) to ongoing therapy with metformin in combination with rosiglitazone in a total of 277 patients with type 2 diabetes with a mean baseline $\mathrm{HbA}_{1 \mathrm{c}}$ of $8.8 \% .^{57}$ The addition of sitagliptin reduced $\mathrm{HbA}_{1 \mathrm{c}}$ by $0.9 \%$ versus a reduction by $0.2 \%$ in patients who continued on metformin and rosiglitazone.

\section{Clinical effects of sitagliptin - summary}

The clinical trials show efficient and sustained (up to 2 years) improvement of glycemic control of sitagliptin both in monotherapy and in combination with metformin, glimepiride, pioglitazone and insulin and also improved effect when used in triple therapy together with metformin plus glimepiride or metformin plus rosiglitazone. In general, $\mathrm{HbA}_{1 \mathrm{c}}$ was reduced by sitagliptin by $\approx 0.6 \%$ to $1.0 \%$ from baseline levels of $7.5 \%$ to $8.8 \%$. An active comparative study has shown similar effect as glipizide when added to metformin. ${ }^{54}$ The effect of sitagliptin seems to be similar to other DPP-4 inhibitors, although head-to-headstudies have not been undertaken. ${ }^{41,44,46,47,58-69}$ Figure 4 shows the reduction in $\mathrm{HbA}_{1 \mathrm{c}}$ during 24- to 26-week studies with four different DPP-4 inhibitors as monotherapy or in combination with metformin, a sulfonylurea or a thiazolidinedione. Initial $\mathrm{HbA}_{1 \mathrm{c}}$ levels differed in the different studies; overall no clear difference between the various DPP-4 inhibitors is evident.

\section{Sitagliptin - safety and tolerability Adverse events}

The extensive experience with DPP-4 inhibition that now exists in clinical trials shows high tolerability and safety. 


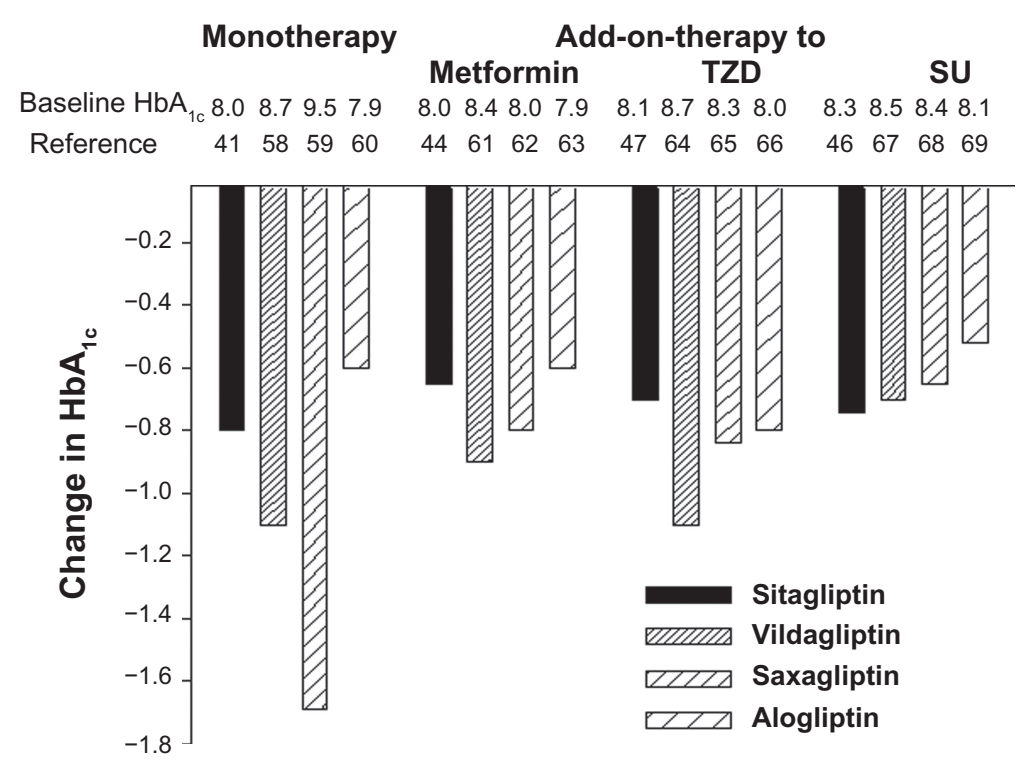

Figure 4 Changes in $\mathrm{HbA}_{\mathrm{Ic}}$ during 24-26 weeks treatment with four different DPP-4 inhibitors in clinical trials, as monotherapy or as add-on to metformin, a thiazolidinedione (TZD) or a sulfonylurea (SU). Baseline $\mathrm{HbA}_{\mathrm{Ic}}$ levels above column.

This is evident from results in several studies with a number of different DPP-4 inhibitors, which show that the number of adverse events is not increased in study groups treated with DPP-4 inhibitors compared to placebo groups, and the drop out rates from studies due to adverse events are low. This is evident also for sitagliptin, ${ }^{35-57}$ and notably also in elderly patients ${ }^{53}$ and in patients with moderate or severe renal insufficiency. ${ }^{52} \mathrm{~A}$ meta-analysis has been published in regard to adverse events with sitagliptin in 12 large, doubleblind studies with durations from 18 weeks to 2 years. ${ }^{70}$ The meta-analysis comprised a total of 3415 patients treated with sitagliptin (100 mg daily) and 2724 controls, who were treated either with other antihyperglycemic agents or placebo. The overall incidence of adverse events in these studies was $63 \%$ in patients given sitagliptin versus $63 \%$ in controls, ie, the same degree of total number of events. Serious adverse events were also similar in the two groups $(7 \%)$ as was the number of patients who discontinued therapy ( $35 \%$ vs $36 \%$ ) or withdrew from the studies due to adverse events ( $3 \%$ vs $4 \%$ ). Some adverse events occurred, however, during the treatment with sitagliptin, although the pattern differed between different studies. When used as add-on to metformin adverse events were absent more frequently with sitagliptin versus metformin alone. When used as initial combination with metformin or as add-on to thiazolidinedione, the most frequent adverse events occurring more commonly in the sitagliptin group were headache and upper respiratory tract infection $(5 \%-6 \%$ vs $3 \%-5 \%$ with metformin or thiazolodinedione alone), and most frequent adverse events for sitagliptin when combined with sulfonylurea were hypoglycemia ( $12 \%$ vs $2 \%)$, nasopharyngitis ( $6 \%$ vs $5 \%)$ and headache (6\% vs $2 \%)$. Furthermore, sitagliptin seems to be safe from a cardiovascular point of view, since adverse events suggestive of cardiac disorders (such as acute coronary syndrome, acute myocardial infarction or angina pectoris) were absent more frequently in patients treated with sitagliptin versus comparators or placebo. ${ }^{70}$

Following the reports of acute pancreatitis in subjects treated with exenatide or sitagliptin, concern has been raised that incretin based therapy is associated with increased risk of acute pancreatitis. This is difficult to establish because there is a generalized increased risk of acute pancreatitis in patients with diabetes, obesity or hyperlipemia. A claims-based drug surveillance system has, however, shown that the risk for pancreatitis is not higher when patients are treated with sitagliptin (or exenatide) than when treated with metformin or sulfonylurea. ${ }^{71}$ Also a few serious hypersensitivity reactions have been reported during treatment with sitagliptin. Therefore, although being extremely well tolerated in studies up to 2 years, long-term surveillance is of importance for the detection of potential adverse events that might occur at later stages or infrequently during treatment with sitagliptin.

\section{Hypoglycemia}

Hypoglycemia is rare $(<3 \%)$ during treatment with DPP-4 inhibitors as monotherapy or in combination with metformin or thiazolidinediones. ${ }^{35-38,41-45,47,53}$ The low degree of 
hypoglycemia is especially seen when compared with the risk of hypoglycemia during treatment with sulfonylurea (Figure 4). This is explained by the glucose-dependency of the islet effects of GLP-1; hence when glucose levels are reduced the effects of GLP-1 in stimulating insulin secretion and inhibiting glucagon secretion vanish. In contrast, hypoglycemia was shown to be more common when sitagliptin was added to ongoing glimepiride; the incidence of hypoglycemia was $12 \%$ versus $2 \%$ in the group given glimepiride alone. ${ }^{46}$ The potential risk for hypoglycemia when combining sitagliptin and sulfonylureas may be due to an uncoupling mechanism of sulfonylureas of the glucose dependency of the islet actions by GLP- $1 .^{72}$ This risk needs, however, to be evaluated in more detail. If increased frequency of hypoglycemia when combining sitagliptin with a sulfonylurea is confirmed, a clinical consequence is that the dose of sitagliptin or sulfonylureas should be reduced when these are used in combination. Similarly, when combined with insulin, there was an increased risk for hypoglycemia by sitagliptin. ${ }^{56}$

In spite of the very low risk of hypoglycemia during treatment with DPP-4 inhibition, a concern might be that if hypoglycemia nevertheless evolves, DPP-4 inhibition might compromise the counterregulation, if it is associated with inhibition of glucagon secretion also under these conditions. A recent study addressed this by examining the glucagon response to hypoglycemia in patients treated with the DPP4 inhibitor vildagliptin. ${ }^{73}$ It was found that contrary to the inhibition of glucagon secretion after meal ingestion by vildagliptin, ie, when glucose levels are elevated, the glucagon response to hypoglycemia was not inhibited. ${ }^{72}$ This preserved glucagon secretion during hypoglycemia in patients treated with vildagliptin suggests that DPP-4 inhibition prevents hypoglycemia. This prevention may be due to improved glucose sensing in the $\alpha$-cells such that DPP-4 inhibition, through GLP-1, restores and improves the action of glucose on glucagon secretion, ie, it augments the inhibition of glucagon secretion at high glucose but exaggerates the stimulation of glucagon secretion at low glucose. A similar study with sitagliptin is warranted to examine whether sitagliptin, like vildagliptin, would prevent hypoglycemia.

\section{Sitagliptin - other potential effects Body weight}

Many studies show that sitagliptin is body weight neutral. ${ }^{41-47,51,54,57}$ Therefore, when compared to thiazolidinediones, sulfonylureas and insulin, DPP-4 inhibition shows advantage compared to the increase in body weight which is associated with these other treatments. This is clearly evident when compared with glipizide, which increased body weight, whereas sitagliptin was body weight neutral over a study period of 52 weeks (Figure $4^{54}$ ).

\section{Lipids}

In clinical studies with sitagliptin, there has been either no significant change in lipids ${ }^{42,47}$ or small beneficial effects on blood lipids. ${ }^{44,45}$ The two studies reporting effects showed that when sitagliptin was added to metformin, total cholesterol was reduced by $3 \%$ to $6 \%$, triglycerides were reduced by $17 \%$, non-high-density lipoptrotein (HDL)-cholesterol was reduced by $10 \%$ to $19 \%$ and HDL-cholesterol was increased by $2 \% .{ }^{44,45}$ Potential long-term effects of sitagliptin on lipids remain to be established.

\section{Sitagliptin - regulatory aspects}

Sitagliptin (Januvia ${ }^{\circledR}$; Merck) was approved by the Food and Drug Administration (FDA) in October 2006 and by the European Medicines Agency (EMEA) in April 2007. It is at present approved in 85 countries throughout the world. It is indicated for use as monotherapy and in combination therapy. As monotherapy, the indication in the US is as an adjunct to diet and exercise to improve glycemic control in patients with type 2 diabetes, whereas in the EU, it is indicated as monotherapy in patients who have inadequate glycemic control with diet and exercise and in whom metformin is inappropriate due to contraindications or intolerance. Sitagliptin is also indicated, both in the US and in EU, in combination therapy with metformin, a sulfonylurea or a thiazolidinedione in patients who have inadequate control with these agents used as single agents plus diet and exercise. Recently, sitagliptin was also approved to be used in combination with insulin. Sitagliptin is also indicated as triple therapy in combination with metformin plus a sulfonylurea or metformin plus a thiazolidinedione in patients who have inadequate glycemic control with the two agents.

The recommended dose for sitagliptin is $100 \mathrm{mg}$ daily as a single tablet. When used as add-on to metformin or thiazolidinediones, the doses of these agents can be maintained, whereas when added to a sulfonylurea it is recommended that the dose of the sulfonylurea is reduced. Sitagliptin exists also as a combination tablet with metformin. The tablets contain $50 \mathrm{mg}$ sitagliptin and $850 \mathrm{mg}$ metformin $\left(\right.$ Janumet $\left.^{\mathbb{}}\right)$. The recommended dose of these tablets is twice daily, which is equivalent to $100 \mathrm{mg}$ sitagliptin daily.

In the US the dose of sitagliptin is recommended to be lowered in subjects with renal insufficiency: $50 \mathrm{mg}$ 
daily in moderate renal insufficiency (creatinine clearance $30-50 \mathrm{~mL} / \mathrm{min}$ ), and $25 \mathrm{mg}$ daily in severe renal insufficiency (creatinine clearance $<30 \mathrm{~mL} / \mathrm{min}$ ). In the EU, sitagliptin is not recommended in subjects with renal insufficiency.

\section{Conclusions and clinical positioning of sitagliptin}

DPP-4 inhibition as a novel therapy of type 2 diabetes improves islet function due to the increased concentrations of active GLP-1, which stimulates insulin secretion and inhibits glucagon secretion. Since these effects target main pathophysiologic defects in type 2 diabetes, DPP-4 inhibition is a treatment targeting pathophysiologically relevant aspects of the disease. The therapy therefore holds the promises of improving basis of the disease and may therefore be the solution to several of the currently unmet needs for treatment of the disease. Clinical trials also show the efficacy of the strategy, and the safety profile shows low risk for adverse events or hypoglycemia. DPP-4 inhibition is therefore a novel and promising paradigm for treatment of type 2 diabetes.

Sitagliptin is a DPP-4 inhibitor which has shown good clinical effect in reducing glycemia both as monotherapy and in combination with other oral agents and with insulin. Sitagliptin may be of greatest value as add-on to ongoing metformin in patients with inadequate glycemic control when treated with metformin alone or as monotherapy in subjects in whom metformin is contraindicated or in subjects with adverse events from metformin. Initial combination with DPP-4 inhibitors and metformin in drug-naïve patients requiring pharmacological treatment for glycemic control, would be another place of the therapy. The reason for this is that sitagliptin improves pathophysiological defects which are seen early during the progression of diabetes, mainly the islet dysfunction, in association with safety and high tolerability. In particular, the occurrence of hypoglycemia is rare, which makes it of special interest in early stages as well as in elderly patients.

DPP-4 inhibition may be of greatest impact as add-on to metformin in patients with inadequate control of glycemia when treated with metformin alone. The clinician may in such a situation select between a DPP-4 inhibitor and a sulfonylurea. It is therefore of interest that when directly comparing sitagliptin versus glipizide when added to metformin in such patients, the reduction in $\mathrm{HbA}_{1 \mathrm{c}}$ was the same over a 6 month but yet important differences existed. ${ }^{54}$ Thus, whereas glipizide increased body weight, sitagliptin reduced body weight, and whereas glipizide resulted in several events of hypoglycemia, this was rare with sitagliptin (Figure $4^{54}$ ). A similar finding was recently reported also for vildagliptin after 1 year of treatment when added to metformin versus glimepiride. ${ }^{74}$ Hence, although long term comparisons are required, DPP-4 inhibition offers a better outcome than sulfonylurea when added to metformin over a duration of 6 months to 1 year.

Sitagliptin may also be exchanged for sulfonylurea or thiazolidinediones in combination with metformin in subjects with intolerance to sulfonylurea or thiazolidindediones or with inadequate glycemic control with these combinations. This might also be a useful indication, considering the limitation when using sulfonylureas or thiazolidinediones in terms of adverse events. Furthermore, DPP-4 inhibition has also an important place as add-on to sulfonylurea or thiazolidinediones in subjects with inadequate glycemic control when treated with these agents alone. A potential future combination is DPP-4 inhibition plus insulin, in more advanced stages of the disease. Hence, DPP-4 inhibition may be used both in early stages of the diseases, as monotherapy or in combination therapy, as well as in more advanced stages of the disease. This is in line with a recent algorithm for glycemic control as stated by an American Association of Clinical Endocrinologists/American College of Endocrinology Consensus Panel. ${ }^{75}$

The evidence for the beneficial effect of sitagliptin is its efficacy in improving glycemic control in studies over 6 to 12 months in association with safety and low risk of adverse events. The long-term durability is now important to consider and of high importance for the future long-term value of this class of compounds. Whether sitagliptin may have additional beneficial effects on islet mass, as has been shown in rodents, ${ }^{26}$ remains to be established in humans.

In the clinical context, sitagliptin offers similar indication as the other DPP-4 inhibitors and the GLP-1 receptor agonists. Sitagliptin is very similar to the other DPP-4 inhibitors on the market, vildagliptin and saxagliptin, ${ }^{20}$ and no long-term head-to-head study exists yet for these; it is therefore not possible yet to differentiate between them. Of the GLP-1 receptor agonists (GLP-1 mimetics), exenatide (Byetta $^{\circledR}$; Amylin and Eli Lilly) and liraglutide (Victoza ${ }^{\circledR}$; Novo Nordisk) have been approved for therapy and several others are in clinical development, such as lixisenatide, albiglutide and taspoglutide. They are DPP-4 resistant compounds which are based either on modification of the GLP-1 molecule or based on the peptide exendin-4. ${ }^{76}$ The GLP-1 mimetics are given through the subcutanoues route either once or twice daily or with longer intervals, such as once 
weekly. The efficacy of these compounds seems to be similar as that of the DPP-4 inhibitors. The main differences are that GLP-1 receptor agonists reduce body weight, whereas DPP-4 inhibitors are body weight neutral; that GLP-1 mimetics are injectables, whereas DPP-4 inhibitors are active after oral administration; and that DPP-4 inhibitors are virtually free from adverse events, whereas GLP-1 mimetics are associated with nausea.

Sitagliptin, like the other DPP-4 inhibitors, has a higher cost per day of clinical use than sulfonylureass, which is an economic drawback for the DPP-4 inhibitors. However, a health economic model analysis has shown that addition of sitagliptin to metformin was cost saving compared to sulfonylurea or a thiazolidinedione in patients with inadequate glycemic control on metformin alone. ${ }^{77}$ Nevertheless, more studies are required on this issue.

For future studies, it is important to examine the durability and long-term effects and safety of sitagliptin. Studies are also required to compare the long-term effects in head-to-head studies with other DPP-4 inhibitors and with GLP-1 mimetics. Moreover, outcome studies in relation to co-morbidity, such as cardiovascular diseases, are required. Recently, Merck and Co. has initiated a clinical cardiovascular study with sitagliptin entitled "A randomized placebo controlled clinical trial to evaluate cardiovascular outcomes after treatment with sitagliptin in patients with type 2 diabetes mellitus and inadequate glycemic control on mono- or dual combination oral antihyperglycemic therapy" (TECOS). ${ }^{78}$ This is a long-term event-driven study with the primary objective of evaluating cardiovascular endpoints in high-risk populations; results are expected in 2014. Furthermore, more mechanistic studies are required to establish more detailed information on how sitagliptin affects islet function, including effects on glucagon secretion, and also effects on incretin hormone secretion and metabolism; most mechanistic studies on DPP-4 inhibition exist for vildagliptin. ${ }^{79}$ Studies directed at establishing potential contribution of the incretin hormone GIP, the level of which also is increased by DPP-4 inhibition. Finally, since sitagliptin relies on incretins which are released after meal ingestion, it is important to study their effects in relation to ingestion of various meal ingredients, since it is known that macronutrients have different effects on the release and concentrations of incretin hormones. ${ }^{80}$ Therefore, although much information exists on clinical effects and mechanisms of DPP-4 inhibition, more information is required for a fuller understanding of this promising concept to treat subjects with type 2 diabetes.

\section{Disclosure}

The author has received consulting fees from Merck, Novartis, AstraZeneca, GSK, Roche, Sanofi-Aventis and Servier.

\section{References}

1. Fonseca V. Clinical significance of targeting postprandial and fasting hyperglycemia in managing type 2 diabetes mellitus. Curr Med Res Opin. 2003;19:635-641.

2. Skyler JS, Bergenstal R, Bonow RO, et al. Intensive glycemic control and the prevention of vardiovascular events: implications of the ACCORD, ADVANCE, and VA Diabetes Trials: a position statement of the American Diabetes Association and a Scientific Statement of the American College of Cardiology Foundation and the American Heart Association. J Am Coll Cardiol. 2009;53:298-304.

3. Nathan DM, Buse JB, Davidson MB, et al. Medical management of hyperglycemia in type 2 diabetes: a consensus statement of the American Diabetes Association and the European Association for the Study of Diabetes. Diabetes Care. 2009;32:193-203.

4. Owens DR, Zinman B, Bolli GB. Insulins today and beyond. Lancet. 2001;358:739-746.

5. Hsia SH, Davidson MB. Established therapies for diabetes mellitus. Curr Med Res Opin. 2002;18: Suppl 1:S13-S21.

6. Rendell M. The role of sulphonylureas in the management of type 2 diabetes mellitus. Drugs. 2004;64:1339-1358.

7. Diamant M, Heine RJ. Thiazolidinediones in type 2 diabetes mellitus: current clinical evidence. Drugs. 2003;63:1373-1405.

8. Hussein Z, Wentworth JM, Nankervis AJ, et al. Effectiveness and side effects of thiazolidinediones for type 2 diabetes: real-life experience from a tertiary hospital. Med J Austr. 2004;181:536-539.

9. Dunning BE, Foley JE, Ahrén B. Alpha cell function in health and disease: influence of glucagon-like peptide-1. Diabetologia. 2005;48:1700-1713.

10. Lehy JL. Pathogenesis of type 2 diabetes mellitus. Arch Med Res. 2005;36:197-209.

11. Wajchenberg BL. $\beta$-cell failure in diabetes and preservation by clinical treatment. Endocr Rev. 2007;28:187-218.

12. Inzucchi S. Oral antihyperglycemic therapy for type 2 diabetes. JAMA. 2002;287:360-372.

13. Bailey CJ. Drugs on the horizon for diabesity. Curr Diab Rep. 2005;5:353-359.

14. Ahrén B. Exenatide: a novel treatment of type 2 diabetes. Therapy. 2005;2:207-222.

15. Croom KF, McCormack PL. Liraglutide: a review of its use in type 2 diabetes. Drugs. 2009;69:1985-2004.

16. Drucker DJ, Nauck MA. The incretin system: glucagon-like peptide-1 receptor agonists and dipeptidyl peptidase-4 inhibitors in type 2 diabetes. Lancet. 2006;368:1696-1705.

17. Ahrén B. Glucagon-like peptide-1 (GLP-1): a gut hormone of potential interest in the treatment of diabetes. Bioessays. 1998;20:642-651.

18. Ahrén B. DPP-4 inhibitors. Best Pract Res Clin Endocrinol Metab. 2007;21:517-533.

19. Ahrén B. Dipeptidyl peptidase-4 inhibitors: clinical data and clinical implications. Diabetes Care. 2007;30:1344-1350

20. Ahrén B: Clinical results of treating type 2 diabetic patients with sitagliptin, vildagliptin or saxagliptin - diabetes control and potential adverse events. Best Pract Res Clin Endocrinol Metab. 2009;23: 487-498.

21. Ahrén B, Landin-Olsson M, Jansson PA, et al. Inhibition of dipeptidyl peptidase-4 reduces glycemia, sustains insulin levels and reduces glucagon levels in type 2 diabetes. $J$ Clin Endocrinol Metab. 2004;89: 2078-2084.

22. Ahrén B, Pacini G, Foley JE, Schweizer A. Improved meal-related beta-cell function and insulin sensitivity by the dipeptidyl peptidase-IV inhibitor vildagliptin in metformin-treated patients with type 2 diabetes over 1 year. Diabetes Care. 2005;28:1936-1940. 
23. Balas B, Baig MR, Watson C, et al. The dipeptidyl peptidase IV inhibitor vildagliptin suppresses endogenous glucose production and enhances islet function after single dose administration in type 2 diabetic patients. J Clin Endocrinol Metab. 2007;92:1249-1255.

24. Ahrén B, Simonsson E, Larsson H, et al. Inhibition of dipeptidyl peptidase IV improves metabolic control over a 4 week study period in type 2 diabetes. Diabetes Care. 2002;25:869-875.

25. Brazg R, Xu L, Dalla Man C, et al. Effect of adding sitagliptin, a dipeptidyl peptidase-4 inhibitor, to metformin on 24-h glycaemic control and beta-cell function in patients with type 2 diabetes. Diabet Obes Metab. 2007;9:186-193.

26. Mu J, Petrov A, Eiermann GJ, Woods J, Zhou YP, Li Z, et al. Inhibition of DPP-4 with sitagliptin improves glycemic control and restores islet cell mass and function in a rodent model of type 2 diabetes. Eur J Pharmacol. 2009;623:148-154.

27. Ahrén B, Sörhede Winzell M, Wierup N, et al. DPP-4 inhibition improves glucose tolerance and increases insulin and GLP-1 responses to gastric glucose in association with normalized islet topography in mice with beta-cell specific overexpression of human islet amyloid polypeptide. Regul Pept. 2007;143:97-103.

28. Kim D, Wang L, Beconi M, etal. (2R)-4-oxo-4-[3-(trifluoromethyl-5,6-dihy dro[1,2,4]triazolo[4,3-a]pyrazin-7(8H)-yl]-1-(2,4,5-trifluorophenyl)butan2-amine: a potent, orally active dipeptidyl peptidase IV inhibitor for the treatment of type 2 diabetes. J Med Chem. 2005;48:141-151.

29. Herman GA, Stevens C, van Dyck K, et al. Pharmacokinetic and pharmacodynamics of sitagliptin, an inhibitor of dipeptidyl peptidase IV, in healthy subjects: results from two randomized, double-blind, placebo-controlled studies with single oral doses. Clin Pharmacol Ther. 2005;78:675-688.

30. Herman GA, Bergman A, Stevens C, et al. Effect of single oral doses of sitagliptin, a dipeptidyl peptidase-4 inhibitor, on incretin and plasma glucose levels following an oral glucose tolerance test in patients with type 2 diabetes. J Clin Endocrinol Metab. 2006;91:4612-4619.

31. Bergman A, Ebel D, Liu F, et al. Absolute bioavailability of sitagliptin, an oral dipeptidyl peptidase-4 inhibitor, in an oral dipeptidyl peptidase-4 inhibitor, in healthy volunteers. Biopharm Drug Dispos. 2007;28:315-322.

32. Vincent SH, Reed JR, Bergman AJ, et al. Metabolism and excretion of the DPP-4 inhibitor [14C] sitagliptin in humans. Drug Metab Dispos. 2007;35:533-538.

33. Bergman AJ, Steven C, Zhou, et al. Pharmacokinetic and pharmacodynamic properties of multiple oral doses of sitagliptin, a dipeptidyl peptidase IV inhibitor: a double-blind randomized, placebo-controlled study in healthy male volunteers. Clin Ther. 2006;28:55-72.

34. Herman GA, Bergman A, Liu F, et al. Pharmacokinetics and pharmacodynamic effects of the oral DPP-4 inhibitor sitagliptin in middle-aged obese subjects. J Clin Pharmacol. 2006;46:876-886.

35. Mohan V, Yang W, Son HY, et al. Efficacy and safety of sitagliptin in the treatment of patients with type 2 diabetes in China, India and Korea. Diab Res Clin Pract. 2009;83:106-116.

36. Nonaka K, Kakikawa T, Sato A, et al. Efficacy and safety of sitagliptin monotherapy in Japanese patients with type 2 diabetes. Diabet Res Clin Pract. 2008;79:291-298.

37. Kadowaki T, Tajima N, Odawara M, Nishi M, Nonaka K, Stein PP. Sitagliptin added to ongoing treatrment with metformin improved glycemic control and was well tolerated in Japenese patients with type 2 diabetes. Diabetes. 2008; Suppl 1:A589-590.

38. Nonaka K, Tsubouchi H, Okuyama K, Fukao Y, Johnson-Levonas AO, Amatruda JM. Effects of once-daily sitagliptin on 24-h glucose control following 4 weeks of treatment in Japanese patients with type 2 diabetes mellitus. Horm Metab Res. 2009;41:232-237.

39. Kashiwagi A, Tajima N, Kadowaki T, et al. Sitagliptin added to ongoing treatment with pioglitazone improved glycemic control and was well tolerated in Japanese patients with type 2 diabetes. Diabetes. 2008; Suppl 1:A590.

40. Tajima N, Kadowaki T, Odawara M, Nishi M, Nonaka K, Stein PP. Sitagliptin added to ongoing treatment with glimepiride improved glycemic control and was well tolerated in Japanese patients with type 2 diabetes. Diabetes. 2008;57:Suppl 1:A589
41. Aschner P, Kipnes MS, Lunceford JK, Sanchez M, Mickel C, WilliamsHerman DE. Effect of the dipeptidyl peptidase-4 inhibitor sitagliptin as monotherapy on glycemic control in patients with type 2 diabetes. Diabetes Care. 2006;29:2632-2637.

42. Raz I, Hanefeld M, Xu L, Caria C, Williams-Herman D, Khatami H, Efficacy and safety of the dipeptidyl peptidase- 4 inhibitor sitagliptin as monotherapy in patients with type 2 diabetes mellitus. Diabetologia. 2006;49:2564-25671.

43. Goldstein BJ, Feinglos MN, Lunceford JK, Johnson J, WilliamsHerman DE. Effect of initial combination therapy with sitagliptin, a dipeptidyl peptidase-4 inhibitor, and metformin on glycemic control in patients with type 2 diabetes. Diabetes Care. 2007;30:1979-1987.

44. Charbonnel B, Karasik A, Liu J, Wu M, Meininger G. Efficacy and safety of the dipeptidyl peptidase-4 inhibitor sitagliptin added to ongoing metformin therapy in patients with type 2 diabetes inadequately controlled with metformin alone. Diabetes Care. 2006;29: 2638-2643.

45. Scott R, Wu L, Sanchez M, Stein P. Efficacy and tolerability of the dipeptidyl peptidase-4 inhibitor sitagliptin as monotherapy over 12 weeks in patients with type 2 diabetes. Int J Clin Pract. 2007;61: 171-180.

46. Hermansen K, Kipnes M, Luo E, Fanurik D, Khatami H, Stein P. Efficacy and safety of the dipeptidyl peptidase- 4 inhibitor, sitagliptin, in patients with type 2 diabetes mellitus inadequately controlled on glimepiride alone or on glimepiride and metformin. Diabet Obes Metab. 2007;9:733-745.

47. Rosenstock J, Brazg RG, Andryuk PJ, Lu K, Stein P. Efficacy and safety of the dipeptidyl peptidase-4 inhibitor sitagliptin added to ongoing pioglitazone therapy in patients with type 2 diabetes: a 24-week, multicenter, randomized, double-blind, placebo-controlled, parallel-group study. Clinical Ther. 2006;28:1556-1568.

48. Alba M, Sheng D, Guan Y, et al. Sitagliptin $100 \mathrm{mg}$ daily effect on DPP-4 inhibition and compound-specific glycemic improvement. Curr Med Res Opin. 2009;25:2507-2514.

49. Aaboe K, Vilsbøll T, Knop FK, et al. Twelve weeks treatment with the DPP-4 inhibitor, sitagliptin, improves the insulin secreting capacity of the $\beta$-cells in subjects with type 2 diabetes mellitus: a randomized trial. Diabetes. 2009; Suppl 1:A163.

50. Hanefeld M, Herman GA, Wu M, Mickel C, Sanchez M, Stein PP. Once-daily sitagliptin, a dipeptidyl peptidase-4 inhibitor, for the treatment of patients with type 2 diabetes. Curr Med Res Opin. 2007;23: 1329-39.

51. Qi DS, Teng R, Jiang M, et al. Two-year treatment with sitagliptin and initial combination therapy of sitagliptin and metformin provides substantial and durable glycaemic control in patients with type 2 diabetes. Diabetologia. 2008;51:Suppl 1:S36.

52. Chan JCN, Scott R, Arjona Ferreira JC, et al. Safety and efficacy of sitagliptin in patients with type 2 diabetes and chronic renal insufficiency. Diabetes Obes Metab. 2008;10:545-555.

53. Barzilai N, Mahoney EM, Guo H, et al. Sitagliptin is well tolerated and leads to rapid improvement in blood glucose the first days of monotherapy in patients aged 65 years and older with TDM. Diabetes. 2009; Suppl 1:A158.

54. Nauck MA, Meininger G, Sheng D, Terranella L, Stein PP. Efficacy and safety of the dipeptidyl peptidase-4 inhibitor, sitagliptin, compared with the sulfonylurea, glipizide, in patients with type 2 diabetes inadequately controlled on metformin alone: a randomized, double-blind, non-inferiority trial. Diabet Obes Metab. 2007;9:194-205.

55. Scott R, Loeys T, Davies MJ, Engel SS. Efficacy and safety of sitagliptin when added to ongoing metformin therapy in patients with type 2 diabetes. Diabetes Obes Metab. 2008;10:959-969.

56. Vilsbøll T, Rosenstock JM, Yki-Järvinen H, et al. Efficacy and safety of sitagliptin when added to insulin therapy in patients with type 2 diabetes. Diabetes Obes Metab. 2010;12:167-177.

57. Arjona Ferreira JC, Dobs A, Goldstein BJ, et al. Triple combination therapy with sitagliptin, metformin and rosiglitazone improves glycaemic control in patients with type 2 diabetes. Diabetologia. 2008;51:Suppl 1: S365. 
58. Rosenstock J, Baron MA, Dejager S, Mills D, Schweizer A. Comparison of vildagliptin and rosglitazone monotherapy in patients with type 2 diabetes: a 24-week double-blind, randomized trial. Diabetes Care. 2007;30:217-223.

59. Jadzinsky M, Pfützner A, Paz-Pacheco E, Xu Z, Allen E, Chen R. Saxagliptin given in combination with metformin as initial therapy improves glycaemic control in patients with type 2 diabetes comperaed with either monotherapy: a randomized controlled trial. Diabetes Obes Metab. 2009;11:611-622.

60. DeFronzo RA, Fleck PR, Wilson CA, Mekki Q. Efficacy and safety of the dipeptidyl peptidase-4 inhibitor alogliptin in patients with type 2 diabetes and inadequate glycemic control: a randomized, double-blind, placebo-controlled study. Diabetes Care. 2008;31:2315-2317.

61. Bolli G, Dotta F, Rochotte E, Cohen SE. Efficacy and tolerability of vildagliptin vs pioglitazone when added to metformin: a 24-week randomized, double-blind study. Diabet Obes Metab. 2008;10:82-90.

62. DeFronzo RA, Hissa MN, Garber AJ, et al. The efficacy and safety of saxagliptin when added to metformin therapy in patients with inadequately controlled type 2 diabetes with metformin alone. Diabetes Care. 2009;32:1649-1655.

63. Nauck MA, Ellis GC, Fleck PR, Wilson CA, Mekki Q. Efficacy and safety of adding the dipeptidyl peptidase-4 inhibitor alogliptin to metformin therapy in patients with type 2 diabetes inadequately controlled with metformin monotherapy: a multicentre, randomized, double-blind, placebo-controlled study. Int J Clin Pract. 2009;63:46-55.

64. Garber AJ, Schweizer A, Baron MA, Rochotte E, Dejager S. Vildagliptin in combination with pioglitazone improves glucaemic control in patients with type 2 diabetes failing thiazolidinedione monotherapy: a randomized, placebo-controlled study. Diabet Obes Metab. 2007;9: 166-174.

65. Hollander P, Li J, Allen E, Chen R. Saxagliptin added to a thiazolidinedione improves glycemic control in patients with type 2 diabetes and inadequate control on thiazolidinedione alone. J Clin Endocrinol Metab. 2009;94:4810-4819

66. Pratley RE, Reusch JE, Fleck PR, Wilson CA, Mekki Q. Efficacy and safety of the dipeptidyl peptidase-4 inhibitor alogliptin added to pioglitazone in patients with type 2 diabetes: a randomized, double-blond, placebo-controlled study. Curr Med Res Opin. 2009;25: 2361-2371.

67. Garber AJ, Foley JE, Banerhi MA, et al. Effects of vildagliptin on glucose control in patients with type 2 diabetes inadequately controlled with a sulphonylurea. Diabet Obes Metab. 2008;10:1047-1056.
68. Chacra AR, Tan GH, Apanovitch A, Ravichandran S, List J, Chane R Saxagliptin added to submaximal dose of sulphonylurea improves glucaemic control compared with uptitration of sulphonylurea in patients with type 2 diabetes: a randomized controlled trial. Int J Clin Pract. 2009;63:1395-1406.

69. Pratley RE, Kipnes MS, Fleck PR, Wilson C, Mekki Q. Efficacy and safety of the dipeptidyl peptidase-4 inhibitor alogliptin in patients with type 2 diabetes inadequately controlled by glyburide monotherapy. Diabet Obes Metab. 2009;11:167-176.

70. Williams-Herman D, Round E, Swern A, et al. Safety and tolerability of sitagliptin in patients with type 12 diabetes: a pooled analysis. $B M C$ Endocr Disord. 2008;8:14.

71. Dore DD, Seeger JD, Arnold Chan K. Use of claims-based active drug safety surveillance system to assess the risk of acute pancteatitis with exenatide or sitagliptin compared to metformin or glyburide. Curr Med Res Opin. 2009;25:1019-1027.

72. de Heer J, Holst JJ. Sulphonylurea compounds uncouple the glucose dependence of the insulinotropic effect of glucagon-like peptide 1 . Diabetes. 2007;56:438-443.

73. Ahrén B, Schweizer A, Dejager S, et al. Vildagliptin enhances islet responsiveness to both hyper- and hypoglycemia in patients with type 2 diabetes. J Clin Endocrinol Metab. 2009;94:11236-1243.

74. Ferrannini E, Fonseca V, Zinman B, et al. Fifty-two-week efficacy and safety of vildagliptin vs glimepiride in patients with type 2 diabetes mellitus inadequately controlled on metformin monotherapy. Diabetes Obes Metabol. 2009;11:157-166.

75. Rodbard HW, Jellinger PS, Davidson JA, et al. Statement by an American association of clinical endocrinologists/American college of endocrinology consensus panel on type 2 diabetes mellitus: an algorithm for glycemic control. Endocr Pract. 2009; 15:541-559.

76. Ahrén B. Islet G protein-coupled receptors as potential targets for treatment of type 2 diabetes. Nat Rev Drug Discov. 2009;8:369-385.

77. Schwarz B, Gouveia M, Chen J, et al. Cost-effectiveness of sitagliptinbased treatment regimens in European patients with type 2 diabetes and haemoglobin A1c above target on metformin monotherapy. Diabetes Obese Metab. 2008;10 Suppl 1:43-55.

78. www.clinicaltrials.gov (NCT00790205). Accessed February 18, 2010.

79. Ahrén B, Foley JE. The islet enhancer vildagliptin: mechanisms of improved glucose metabolism. Int J Clin Pract. 2008;62: Suppl 159:8-14.

80. Carr RD, Larsen MO, Sörhede Winzell M, et al. Incretin and islet hormonal responses to fat and protein ingestion in healthy men. Am J Physiol. 2008;295:E779-E784.

\section{Publish your work in this journal}

Diabetes, Metabolic Syndrome and Obesity: Targets and Therapy is an international, peer-reviewed open-access journal committed to the rapid publication of the latest laboratory and clinical findings in the fields of diabetes, metabolic syndrome and obesity research. Original research, review, case reports, hypothesis formation, expert opinion and commentaries are all considered for publication. The manuscript management system is completely online and includes a very quick and fair peer-review system, which is all easy to use. Visit http://www.dovepress.com/testimonials.php to read real quotes from published authors. 